\title{
Resilience, Rationalism, and Response in Modern Chinese Social-Ecological Systems
}

\author{
Denise M. Glover ${ }^{1} \cdot$ Jack P. Hayes ${ }^{2} \cdot$ Stevan Harrell ${ }^{3}$ \\ Accepted: 1 January 2021 / Published online: 8 February 2021 \\ (C) The Author(s), under exclusive licence to Springer Science+Business Media, LLC part of Springer Nature 2021
}

The articles in this topical cluster evolved out of a regional symposium centered on the theme of socio-ecological resilience in modern China, held in April 2019 at the University of Puget Sound in Tacoma, Washington. This was the third regional symposium of Sinologists in the Pacific Northwest focused on environment in China, the first of which was organized by Jack Hayes and held at the University of British Columbia in Vancouver BC; the second convened at Kwantlen Polytechnic University in Richmond BC; and the third organized by Denise Glover at the University of Puget Sound. Each conference had a theoretical or topical focus; the theme for the third symposium was socio-ecological resilience.

If we follow Gunderson et al. (2002) in defining resilience as the capacity of a social-ecological system to maintain its functioning in the face of disturbances, it is clear that human manipulation of ecosystems can sometimes interfere with resilience, while at other times it may enhance the capacity for resilience. For example, replacing sloping fields with terraces reduces runoff caused by disturbances in the form of heavy rain events, but replacing traditional varieties of staple crops with modern, engineered varieties that require added water and fertilizer reduces resilience to disturbances in the form of water or fertilizer shortages. Gunderson and Holling (2002) amplified resilience theory analysis by introducing the term panarchy to further elaborate the evolving nature of complex adaptive systems and their hierarchical structures, with implications for ecological, political, institutional, and management systems. The articles in this collection address environmental management and infrastructure intensification at various temporal and spatial

Denise M. Glover

dglover@pugetsound.edu

1 Department of Sociology and Anthropology, University of Puget Sound, Tacoma, WA, USA

2 Kwantlen Polytechnic University, Surrey, Canada

3 University of Washington, 1430 Undine St, Bellingham, WA 98229-2235, USA scales in the Chinese modern era (post 1911), attempting to judge whether such management has enhanced or diminished resilience in a panarchy, and to explain how and why. Specific topics include large-scale agro-political-industrial planning (Harrell), wildfire management (Hayes), traditional medicine production (Glover), agricultural consolidation (Doll), and sedentarization of pastoralist populations (Salimjan).

The context of modern China is particularly revealing of the effects of centralized management on ecosystem resilience, inasmuch as the overall scale of human population and its effect on environment(s) is amplified, management is intense, and centralized political control is effective. Modern Chinese governments, particularly the Communist Party regime that has ruled the People's Republic since its founding in 1949, have committed themselves to a managerial style that expresses faith in the positive effects of human manipulation of ecosystems, believing that intensification of agricultural and industrial production is the method to build a strong, populous, and wealthy country. We believe that examining the ways that planning and development have modified China's ecosystems, particularly in the last 70 years, can contribute to our understanding of the resilience and thereby the sustainability of highly modified social-ecological systems.

Several key themes emerge from our articles, but they are united by a central core tension between rationalist, ex-situ deductive modernism and locally based in-situ empiricism. This tension usually manifests as practices that diminish socio-ecological resilience versus those that enhance such resilience. Often, if not always, the deductive rationalist practices are undertaken in the interest of increasing productivity, but at the same time their effect is to increase the vulnerability and decrease the resilience of social-ecological systems. All the articles illustrate such tensions. During the Great Leap Forward, for example, there was an all-out push to build hundreds of large- and small-scale waterworks projects, in order to increase irrigated area and thus boost crop yields. Many of these projects, however, increased water storage but neglected water drainage, leading to vulnerability to waterlogging when summer rains were especially heavy, and ultimately 
diminishing rather than increasing yields (Harrell). Hayes discusses current fire management techniques in northeast and southwest China, where total fire suppression has led to fewer fires but increased vulnerability to larger-scale and intensive fires, while traditional fire management including prescribed burning reduced fuel load and thus led to more resilience in fire regimes. Glover explores how modernized standardization processes of traditional Tibetan medicine production, based on international and national standards, do not allow for flexibility of natural resource use and lead to rigidity traps, whereas the long-standing traditional practice of ingredient substitution in Tibetan medicine is an adaptive strategy that is crucial for sustainability and resilience of local ecologies. Doll describes how centralgovernment imposed expansion of large-scale farming in Anhui has discouraged adaptive and autonomous smallscale farming, resulting not only in decreased resilience to weather disturbances and pest infestations, but also to lower yields. Salimjan shows how the relocation of Kazakh nomads from their territories near lakes in Xinjiang, intended to both rehabilitate overgrazed pastures and increase nomad household incomes, in fact has done neither, but instead has led to soil degradation, erosion, and increased dependency on artificially constructed infrastructures.

This tension between deductive rationalism and grounded empiricism is reflected in James Scott's discussion in his now classic Seeing Like a State (1998) contrasting the high modernism of the authoritarian state with local knowledge, or mêtis, that comes from lived experience in place and time. Scott describes the work of states - particularly authoritarian ones - as a form of simplification, pursued in the interest of legibility and ultimately of control. He also notes that some non-state actors have similar characteristics and interests: "large-scale capitalism is just as much an agency of homogenization, uniformity, grids, and heroic simplification as the state is" (p. 8). This leads us to consider not only the role of the state, but also the role of capitalism in the economies of natural resource extraction and agriculture, particularly in post-Mao China, and their effect on socio-ecological resilience. Examples of the role of capitalism include standardized medication manufacturing for increased marketization (Glover) and factory farming (Doll), the combination of heavy logging, mono-species afforestation, and fire management leading to the fire paradox (Hayes), as well as the motivations of the tourist companies who moved into the lake district after the Kazakh nomads were moved out (Salimjan). Not coincidentally, these examples of simplification, pursued in the interests of capitalist profit, also serve to enhance interests of state control.

Deductive rationalism, whether coming from the state or the market or both, removes autonomy and flexibility from the local level. Throughout the articles in this topical cluster are examples of top-down panaceas (Ostrom and Cox 2010) that do not result in adaptive and resilient outcomes, and that largely disregard local conditions and local knowledge holders. Perhaps the starkest example is that of China's Great Leap Forward (Harrell), when policy makers at the national level ignored the advice of local farmers, implementing programs developed under wildly different ecological contexts, such as plows built for the Russian steppes, or simply deduced through rationalist logic, such as concluding that since plowing to the depth of a foot increased yields, farmers should plow to a depth of a meter or more. Similar problems accompanied the introduction of large-scale farming in the past decade in Anhui Province, and the relocation of herders in northern Xinjiang; in both cases local farmers and herders lost control over key aspects of their livelihoods, or over the shape of their local landscapes, or both. For example, nominally in the interests of legibility and rationalization, farmers in Anhui had their irrigation ponds filled in and herders in northern Xinjiang were deprived of the pastures they needed to raise their animals and thus of their livelihoods (Doll, Salimjan). Appropriate substitutions in Tibetan medicine formulas that were traditionally the prerogative of practitioners and pharmacists are no longer permissible in government-sponsored and certified medicine (Glover). Local fire conditions and knowledge about those conditions that provided effective management for centuries is no longer considered significant in current top-down fire management planning (Hayes).

Deductive rationalism strives for efficiency, homogenization, and standardization of processes. Agricultural authorities and planners advocate large-scale farming as more labor efficient, but at the price of lower yields per hectare (Doll). Standardization of traditional medicines may be desirable from the perspective of efficiency and safety, but a notable value of traditional medicines is the ability to tailor formulas to local conditions, including practitioner and patient needs as well as natural resource availability (Glover). Planting rice seedlings closer together to increase yields led to competition among plants and exhaustion of soil fertility, and in fact yields decreased (Harrell). Relocating pastoralists was intended to rehabilitate pastures and develop ecotourism, but in fact led to construction of an artificial landscape that requires constant human intervention and cultural assimilation of the Indigenous populations (Salimjan). Standard practices are promoted precisely because deductive rationalism leads to the certainty they will work everywhere regardless of local conditions; heterogeneity comes to be regarded as backward and undesirable while homogeneity is held to embody modernity and progress. But as resilience theory proposes, cutting everything with one knife ( $y i$ dao qie 一刀切) eliminates the diversity that hedges against risk and harms the long-term resilience of social-ecological systems. The two dangers of what Shapiro (2001) calls "dogmatic uniformity," are that when conditions change, adaptation becomes difficult, if not impossible, and that there are no backup strategies to cope with disturbances to a system. In either case, socio-ecological crises may ensue. Historically, we saw just 
these outcomes with the social and ecological collapse precipitated by the Great Leap Forward, and we are seeing them now with increased intensity in fires throughout parts of China, with degraded grasslands, with endangered medicinal species, and with declining rice yields. Whether the future will bring similar collapse to agriculture, animal husbandry, and the natural resources used in traditional medicines remains an open question.

The tension between deductive rationalism and inductive empiricism also results in intriguing paradoxes or contradictions. Hayes explains how management of fires that aims for total control through suppression can in fact increase the likelihood of more intense fires. Glover discusses how innovation, so valued in the marketplace as well as in traditional Tibetan medical praxis, is hindered in traditional medicine production by standardized processes that marketization require. Harrell highlights how ecosystem projects during early collectivization helped increase ecological resilience but failed to work at increased scale with larger projects. Doll illustrates how, in the case of Anhui, large-scale and homogenous farming systems, while possibly more labor efficient, are conversely less efficient per acre. Salimjan shows how quantitative grassland science, intended to restore ecosystems, instead leads to increased dependency on artificial infrastructure, in addition to depriving local pastoralists of livelihood and cultural meaning.

The Chinese Communist Party has long been obsessed with a "bigger is better" model for many infrastructure projects, such as imposing architectural standards for government buildings, construction of the world's largest dam (Three Gorges), and the world's biggest water project, the South-to-North Transfer that transfers over $25 \mathrm{~km}^{3}$ of water each year from the Yangtze to the Yellow River basin. Giant agricultural and water projects, extensive farms, increased scale of industrialization of natural resources with more rigid regulations, and large population transfers are projects that are implemented in the belief that they will bring modernity, prosperity, and plenty. But there are multiple problems with the megaproject approach. Oversized piazzas and dams built to display the grandeur of the Party-state do not have natural limits like ecosystems but natural limits nonetheless remain; it has become increasingly clear that humans are not, as the old saying that Mao adopted goes, destined to conquer nature. At the same time, social-ecological systems become dependent on these big projects; they create rigidity traps (Holling et al. 2002: 95) that limit adaptive capacity and increase vulnerability to large-scale or unanticipated disturbances.

The logic of deductive rationalism leads to the ultimate simplification being imposed through environmental planning and management onto systems that are too complex to understand completely, let alone manipulate reliably. While none of our authors are policy experts, much of what we discuss here points toward policy recommendations based on the issues we have seen as researchers in the fields of anthropology, geography, and history. Attention to local conditions, ground- truthing the results of deductive rationalism, listening to local knowledge, adapting programs to local conditions, and allowing flexibility of responses are all ways to avoid the traps of the top-down, command-and-control management (Holling and Meffe 1996) demonstrated in so many contexts in the articles in this cluster.

Recently, Chinese state planners and intellectuals have recognized, in theory at least, many of the problems and paradoxes we have outlined here. Since 2012, the Xi Jinping regime has promoted "ecological civilization" (shengtai wenming 生态文明) as one of the pillars of the "China Dream" that is the basis of its state legitimacy (Ren 2013; Li and Shapiro 2020). "Ecological civilization" recognizes the limits of ecosystems and decrees that human society and economy should develop in harmony, rather than opposition, with natural ecosystems. Whether this turn in basic philosophy can result in reappraisal and suitable modification of the logic of deductive rationalism applied to date to so many specific places, problems, and peoples is a question whose answer may become apparent in the near future.

Acknowledgements We would like to thank the Asian Studies Program at the University of Puget Sound and the Trimble Foundation for funding the symposium from which these articles developed.

\section{References}

Gunderson, L.H. and C.S. Holling, eds. (2002). Panarchy: Understanding Transformations in Human and Natural Systems. Island Press, Washington, D.C.

Gunderson, L.H., Holling, C.S., Pritchard, L. Jr., and Peterson, G.D. (2002). Resilience of Large-Scale Resource Systems. In L.H. Gunderson and L. Pritchard, Jr., Resilience and the Behavior of Large-Scale Systems. Island Press, Washington, D.C., pp. 3-20.

Holling, C.S., Gunderson, L.H., and Peterson, G.D. (2002). Sustainability and Panarchies. In L.H. Gunderson and C.S. Holling (eds.), Panarchy: Understanding Transformations in Human and Natural Systems. Island Press, Washington, D. C., pp. 63-103.

Holling, C. S. and Meffe, G.K (1996). Command and Control and the Pathology of Natural Resource Management. Conservation Biology 10 (2): 328-337.

Li, Y., and Shapiro, J. (2020). China Goes Green: Coercive Environmentalism for a Troubled Planet. Polity Press, Cambridge.

Ostrom, E., and Cox, M. (2010). Moving Beyond Panaceas: a Multitiered Diagnostic Approach for Social-ecological Analysis. Environmental Conservation 37, 4: 451-63.

Ren Zhongping 任中评 (2013). 生态文明的中国觉醒 (The Awakening of China's Ecological Civilization). Renmin Ribao人民日报 July 22, p. 1.

Scott, J. C. (1998). Seeing Like a State: How Certain Schemes to Improve the Human Condition have Failed. New Haven: Yale University Press.

Shapiro, J. (2001). Mao's War Against Nature. Cambridge University Press, Cambridge.

Publisher's Note Springer Nature remains neutral with regard to jurisdictional claims in published maps and institutional affiliations. 